\title{
Establishment of Africa Red Mahogany (Khaya anthoteca) Pre-Inoculated with Arbuscular Mycorrhizae Fungi (AMF) and Compost Application on an Ex-Coal Mined Site
}

\author{
Philip Worlanyo Dugbley ${ }^{1, \text { *, Irdika Mansur }}{ }^{1,2}$, Basuki Wasis ${ }^{1}$ \\ ${ }^{1}$ Department of Silviculture, Faculty of Forestry, Bogor Agricultural University, Bogor-Indonesia \\ ${ }^{2}$ SEAMEO Biotrop, Jalan Raya Tajur 6K, Bogor, Indonesia
}

Email address:

philidug87@yahoo.com (P. W. Dugbley), irdikam@gmail.com (I. Mansur)

\section{To cite this article:}

Philip Worlanyo Dugbley, Irdika Mansur, Basuki Wasis. Establishment of Africa Red Mahogany (Khaya anthoteca) Pre-Inoculated with Arbuscular Mycorrhizae Fungi (AMF) and Compost Application on an Ex-Coal Mined Site. American Journal of Agriculture and Forestry. Vol. 3, No. 2, 2015, pp. 38-46. doi: 10.11648/j.ajaf.20150302.15

\begin{abstract}
Coal mining provides a means for creating wealth and significantly contributes to export earnings, economic activity and employment whilst supporting regional development. However, coal mining is one of the most severe disturbances in terrestrial ecosystems. Thus, the removal of the natural vegetation and upper soil horizons for mining exploration hinders the establishment and survival of plant and soil microbial communities. Revegetation of ex-coal mined lands is therefore required to enable the recover, as close as possible, to its previous integrity. The establishment of tree species capable of protecting the underlying soil and its micro-fauna and flora is one way of achieving this aim. This study therefore aims to investigate the effect of arbuscular mycorrhizae fungi (AMF) pre-inoculation and compost application on the growth performance of the Africa red mahogany, Khaya anthoteca on an ex-coal mined site. The field design for this study was the completely randomized design (CRD) in factorial experiment. Four (4) levels of each factor namely compost and AMF were used with sixteen treatment combinations and each treatment replicated four times giving sixty four (64) experimental units. The results indicated that compost has significant effect $(\mathrm{P}<0.001)$ on height, diameter and leaf increment with steady increment during this study. There was no significant effect of mycorrhizae treatment as well as interaction between both factors (AMF and compost) on the growth of $K$. anthoteca. However, compost composition from a mixture of Salvinia natans and that prepared from the paddy husk (C3) recorded the highest increment in height of $9.31 \mathrm{~cm}$ while compost from $S$. natans only (C1), rice hull compost; herein known as paddy husk compost $(\mathrm{C} 2)$ and control $(\mathrm{C} 0)$ recorded increments of $9.00 \mathrm{~cm}, 5.78 \mathrm{~cm}$ and 4.47 $\mathrm{cm}$ respectively. The arbuscular mycorrhizae fungi played a role in the survival of the species on the field. There was percentage difference of between 18.5-37.5\% over the control treatment. AMF from Glomus manihotis had the highest percentage survival of $81.25 \%$ whiles the control treatment of mycorrhizae had the lowest percentage of $43.75 \%$. Plants are also able to withstand harsh environmental conditions through fungi-plant symbiosis enhancing the chances of survival on the field and thus, aiding the plant establishment. The study concludes that AMF and compost applications are feasible and sound technologies for the establishment of $K$. anthoteca on ex-coal mined sites.
\end{abstract}

Keywords: Coal Mining, Khaya anthoteca, Plant Growth, Arbuscular Mycorrhizae Fungi (AMF), Compost

\section{Introduction}

Coal mining provides means for creating wealth and enhances export earnings, economic activities as well as employment whilst supporting regional development. For example, the mining sector of Indonesia contributes to the nation's economy currently, for about $11.54 \%$ of total GDP [23].However, coal mining is one of the most severe disturbances in terrestrial ecosystems. It causes large-scale deforestation and land degradation with complete loss of topsoil. Thus, the removal of the natural vegetation and upper soil horizons for exploration and mining that hinders the establishment and survival of plants and soil microbial communities [7]. Mining also results in the formation of artificial habitats that are microbiologically poor, requiring human intervention for their proper restoration [27]. 
Revegetation of coal mined lands is therefore required to enable the re-use of such lands for other purposes. The establishment of tree species capable of protecting the underlying soil and its micro-fauna and flora is one way of achieving this aim.

Khaya anthoteca commonly referred to as the Africa red mahogany is a species belonging to the family Meliaceae. This species is heavily exploited, particularly in East and West of Africa. The species is used in high class cabinetwork and for the production of veneers and any application where good quality, medium weight hardwood is needed [13]. It also weathers well and is resistant to borers and termites. The dense crown makes it suitable as a shade tree and also popular for windbreaks as well as for aesthetic purposes. It has successfully been introduced in South Africa, Cuba and Puerto Rico and on a limited scale in Indonesia and Peninsular Malaysia where it has been used in plantations and also in Taungya systems.

Mycorrhizal fungi have over the years played critical roles in nutrient cycling and the functioning of ecosystems. According to [29], mycorrhiza fungi are the main pathway through which most plants obtain mineral nutrients and as such, are critical in terrestrial ecosystem functioning. In this mutualistic symbiosis, plants exchange photosynthates, not only for mineral nutrients, but also for increased resistance to disease, drought and extreme temperatures. Thus, plants are able to withstand harsh environmental conditions through fungi-plant symbiosis. It also been reported that mycorrhizal fungi are removed entirely in newly graded lands and always requires inoculation if the objective is a functional terrestrial ecosystem. Eroded land is also in nearly the same condition. The arbuscular mycorrhizal fungi (AMF) can therefore be integrated in soil management. These are structures resulting from the symbiosis between these fungi and plant roots, occurring in most soils and colonize roots of many plant species and directly involved in plant mineral nutrition. The symbiotic root-fungal association increases the uptake of less mobile nutrients [21], essentially phosphorus (P) but also of micronutrients like zinc $(\mathrm{Zn})$ and copper $(\mathrm{Cu})$, the symbiosis has also been reported as influencing water uptake. AMF can also benefit plants by stimulating the production of growth regulating substances, increasing photosynthesis, improving osmotic adjustment under drought and salinity stresses as well as increasing resistance to pests and soil borne diseases [1] and benefits have mainly been attributed to improved phosphorous nutrition.

Furthermore, the addition of composted residue is an effective treatment for increasing rhizosphere aggregate stability. Mycorrhiza is increasingly important for improving the growth of seedlings following the addition of composted residue to soil under severe climatological conditions as reported by [6]. They also reported that high proportion of stable aggregates of soil is mainly attributed to a higher microbial activity of root biomass and particularly to the presence of vesicular arbuscular mycorrhiza in the rhizosphere aggregates. At the same time, reforestation techniques based on the addition of composted residue and mycorrhizal inoculation in the nursery could be used as a tool for improving soil structure, with subsequent improvement in plant growth. This study therefore aims to investigate the effect of arbuscular mycorrhizae fungi (AMF) preinoculation and compost applications on the growth performance on vegetatively propagated $K$. anthoteca (Africa red mahogany), on an ex-coal mined site located in South Sumatra of Indonesia.

\section{Materials and Methods}

\subsection{Study Area}

This research was conducted in a coal mining site namely; PT. Bukit Asam located in South Sumatera of Indonesia. South Sumatra falls within coordinates $2^{\circ} 45^{\prime} \mathrm{S} 103^{\circ} 50^{\prime} \mathrm{E}$ of Indonesia. The area is characterized by a bimodal rainfall pattern with the major wet season between May and July. This area experiences a short dry season in August and a long one between December and March. The annual rainfall ranges between $2000 \mathrm{~mm}$ and $3000 \mathrm{~mm}$. The study was conducted from August to December, 2014.

\subsection{Research Materials and Tools}

Materials and tools used for the study included; record log sheets, clip board, pencil, tape measure, electronic caliper, meter rule, analog weighing scale, non-poisonous maker, Microsoft excel and Minitab Version 16. Three-month old $K$. anthoteca seedlings were obtained from Carita, Banten province of West Java, Indonesia.

\subsection{Experimental Design and Layout Procedures}

Thedesign for this field research was the Factorial experiment in Completely Randomized Design (CRD). Two factors; mycorrhizae and compost with four levels of each factor were used giving a total of sixteen (16) treatment combinations and each treatment combination replicated four (4) times. In total, sixty-four (64) experimental units were used for this study. The specified treatments (M) for mycorrhizae were as follows; $\mathrm{M}_{0}$ (control; without mycorrhiza inoculation); $\mathrm{M}_{1}( \pm 50$ single spores of Gigaspora margarita mycorrhizae); $\mathrm{M}_{2}( \pm 50$ spores of Glomus manihotis mycorrhizae); $\mathrm{M}_{3}( \pm 25$ spores each of Gigaspora margarita and Glomus manihotis mycorrhizae). The treatments $(\mathrm{C})$ for compost were; $\mathrm{C}_{0}$ (control; no compost); $\mathrm{C}_{1}( \pm 5 \mathrm{Kg}$ of Salvinia natans compost $) ; \mathrm{C}_{2}( \pm 5 \mathrm{Kg}$ of paddy husk compost); $\mathrm{C}_{3}( \pm 2.5 \mathrm{Kg}$ each of paddy husk and Salvinia natans composts). Planting space of $4 \times 4 \mathrm{~m}$ (625plants/ha) was used and the various treatment combinations were randomly allocated to the plots with each plot having one of the treatment combinations. Reference points of $5 \mathrm{~cm}$ above the soil surface of the seedlings were marked with nonpoisonous indelible ink marker to provide consistency at the point of height and diameter measurements. 


\subsection{Data Collection and Analysis}

The plant parameters measured were the height $(\mathrm{cm})$, stem diameter (mm), leaf counts and percentage survival. According to [17], height and stem diameter are some of the frequently used methods of measuring the growth of multicellular living systems and also often advantageous to use several characteristics for the same system. An indelible ink was used to mark each plantlet $5 \mathrm{~cm}$ above the soil, where the diameter and height readings were taken since irregularity of the soil around the seedlings can affect the recording. Initial measurements of plant parameters were recorded two days after transplanting and fortnightly thereafter over sixteen weeks ( 4 months) of the field research. Data on percentage survival was collected after the field experiment. Data on plant parameters were subjected to a two-way analysis of variance (ANOVA) at a significance level of 5\% (alpha $\leq 0.05$ ). Microsoft excel was used in data entry and computation for the increment of the various plant parameters measured (data management). All statistical analyses were performed using the Minitab statistical analysis package V.16. (Minitab, Inc.). Tukey’s Honest Significant Difference test was used for multiple comparison tests where treatment means differed significantly. The mathematical model for the research design is as follows;

$$
\text { Yijk }=\mu+\tau i+\beta j+(\tau \beta) i j+\varepsilon i j k
$$

Where:

Yijk= the (ijk)th observation for $i=1,2,3$ and 4; $=1,2,3$ and 4 ; and $\mathrm{k}=1,2,3$ and 4

$\mu=$ parameter common to all treatments (the mean) $\tau i=$ the ith treatment effect of factor A (mycorrhizae)

$\beta \mathrm{j}=$ the $\mathrm{jth}$ treatment effect of factor $\mathrm{B}$ (compost)

$(\tau \beta) i j=$ the (ij)th interaction effect of factor A and B

$\varepsilon \mathrm{ijk}=$ random error component with normal distribution

\section{Results and Discussion}

\subsection{Plant Growth}

Growth is the irreversible increase in the size of a plant and has also been considered as the product of its physiological processes. Plants have indeterminate growth, thus, they have the capacity to grow from the apical meristem indefinitely. Growth generally occurs in cycles such as seasonally or daily. Factors affecting the growth of plants are broadly categorized into genetic and environmental factors as well as the interaction between these factors.

\subsection{Growth of K. anthoteca on an Ex-Coal Mined Site}

The growth of plants depends on the availability of nutrients from the soil. Thus, it is important that the soil should continuously provide nutrients for the growth and development of plants [25].
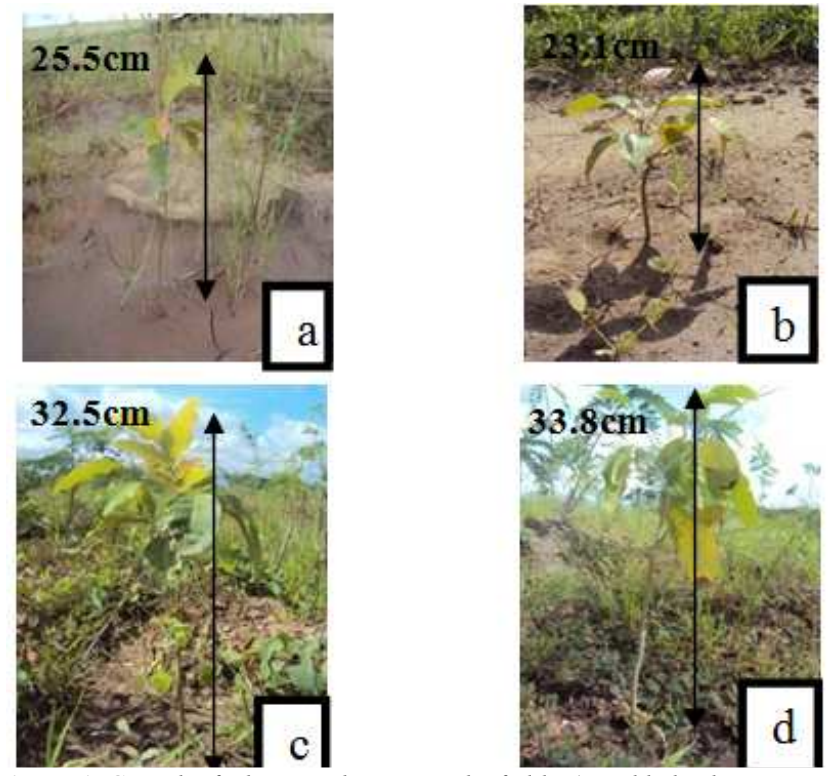

Figure 1. Growth of Khaya anthoteca on the field: a) Paddy husk compost b) Without Compost c) Salvinia natans compost d) Mixed compost.

Compost application to $K$. anthoteca had a significant effect on the height growth of the species. Analysis of variance (ANOVA) tested at $\alpha \leq 5 \%$ showed a significant effect $(\mathrm{P}<0.001)$ of compost on the mean height increment. There was no significant effect $(\mathrm{P}>0.05)$ of mycorrhizae treatment as well as the interaction between both factors (Table 1). Compost composition from a mixture of $S$. natans and that prepared from rice hull (herein known as paddy husk compost) recorded the highest increment in height of $9.31 \mathrm{~cm}$ while compost from $S$. natans only (C1), paddy husk compost (C2) and control (C0) had increments of $9.00 \mathrm{~cm}$, $5.78 \mathrm{~cm}$ and $4.47 \mathrm{~cm}$ respectively. However, there was no difference between increments of $\mathrm{C} 3$ and $\mathrm{C} 1$ (Table 4). An increment of between 29.31-100.22\% of the compost treatment over the control was recorded. The use of compost to enhance the growth of plants has been reported and figure 1 shows the final heights of the plants at the time of termination of this study with the various compost treatments. Compost application significantly enhances mitigate the negative effect of a delay in sowing. The use of compost, therefore, is a sound technology for combating soil degradation and often leads to humus accumulation in the soil and thereby supplying nutrients in several binding forms to the soil matrix. Compost also has dynamic impact on exchange processes between root system and sorption complex. This has mainly been attributed to the humified $\mathrm{OM}$ and the colloid properties of the humic substances [22].

However, the nutrient effect of organic composts depends largely on the transformation processes that take place in the soil after their application. This applies especially to nitrogen $(\mathrm{N})$, for which its plant availability is tightly related to microbial transformations. The results of this study are in conformity to earlier reports that, compost application significantly enhances the growth of plants with respect to height. Effect of compost prepared from organic material, 
thus, $S$. natans at a rate of 3.13 tons/ ha on the increment of $K$. anthoteca height was significantly different from that observed both in the control and compost from a less organic material such as paddy husks (rice hull) compost treatments. Laboratory analysis of paddy husk compost (C2) and composite soil of the research site showed low levels of organic carbon and nitrogen of $5.23 \% ; 1.05 \%$ and $0.39 \%$;
$0.07 \%$ respectively. On the other hand, compost prepared from $S$. natans had $15.94 \%$ of organic carbon and $1.15 \%$ of total nitrogen. According to the European Commission, (2001), the degradability and $\mathrm{C} / \mathrm{N}$ ratio of the organic matter determines whether it comes to a net mineralization or immobilization of $\mathrm{N}$ after the application of an organic fertilizer.

Table 1. Analysis of composts

\begin{tabular}{llll}
\hline No & Parameter & Salvinia natans compost & Rice hull (paddy husk) compost $^{\mathbf{b}}$ \\
\hline 1 & Moisture Content (\%) & 78.27 & 40.28 \\
2 & $\mathrm{pH}$ & 6.96 & 6.55 \\
3 & Ash content (\%) & 49.61 & 72.35 \\
4 & Organic material (\%) & 19.32 & 5.34 \\
5 & Organic carbon $(\%)^{\mathrm{a}}$ & 15.94 & 5.23 \\
6 & $\mathrm{C} / \mathrm{N}$ & 13.86 & 4.98 \\
7 & $\mathrm{~N}(\%)^{\mathrm{a}}$ & 1.15 & 1.05 \\
8 & $\mathrm{P}(\mathrm{mg} / 100 \mathrm{~g})$ & 19.34 & 11.84 \\
9 & $\mathrm{~K}(\mathrm{mg} / 100 \mathrm{~g})$ & 835.84 & 158.67 \\
10 & $\mathrm{Mn}(\mathrm{ppm})^{\mathrm{a}}$ & 914 & 50.32 \\
11 & $\mathrm{Fe}(\mathrm{ppm})^{\mathrm{a}}$ & 12349 & \\
\hline
\end{tabular}

${ }^{\mathrm{a}}$ Sample analyzed at SEAMEO Biotrop. ${ }^{\mathrm{b}}$ Sample analyzed by PT. Bukit Asam (South Sumatra)

Again, phosphorus (P), another important and macro nutrient for plant growth responsible for photosynthesis and energy transfer was relatively high $(19.34 \mathrm{mg} / 100 \mathrm{~g})$ in compost from Salvinia natans as compared to that of community compost from paddy husk of $11.84 \mathrm{mg} / 100 \mathrm{~g}$ (Table 1). Also, according to the [30], compost products contain a considerable variety of macro and micronutrients. Although often seen as a good source of nitrogen, phosphorous, and potassium, compost also contains micronutrients essential for plant growth. Since compost contains relatively stable sources of organic matter, these nutrients are supplied in a slow-release form. It also improves the cation exchange capacity of soils, enabling them to retain nutrients longer. It allows tree crops to more effectively utilize nutrients while reducing nutrient loss by leaching.

Table 2. Two-way analysis of variance for height increment $(\mathrm{cm})$

\begin{tabular}{llllll}
\hline Source & Df & SS & MS & F & P-Value \\
\hline Mycorrhiza & 3 & 3.66 & 1.22 & $0.45^{\text {ns }}$ & 0.72 \\
Compost & 3 & 272.71 & 90.90 & $33.50^{*}$ & 0.00 \\
Interaction & 9 & 22.09 & 2.45 & $0.90^{\mathrm{ns}}$ & 0.52 \\
Error & 48 & 130.26 & 2.71 & & \\
Total & 63 & 428.72 & & & \\
\hline
\end{tabular}

* Significant at alpha $(\alpha) \leq 5 \%{ }^{\mathrm{ns}}$ not significant
Microorganisms can also promote root activities as specific fungi work symbiotically with plant roots, assisting them in the extraction of nutrients from soils. In a symbiotic association, fungus colonizes plant root hairs through the cortex cells and acts as an extension of the root system. This type of association is characterized by the formation of arbuscles (finely branched hyphal structures) in the region of the root cortex that may function as nutrient organs or nutrient exchange sites between the symbionts as well as fungal multiplication. Effect of AMF inoculation to $K$. anthoteca for height increment was not significantly different from the control treatment although the means of the inoculated propagules were relatively higher compared to the control. Glomus manihotis inoculation recorded a height increment of $7.51 \pm 0.62 \mathrm{~cm}$ whiles Gigaspora margarita, mixed culture and the control treatment recorded increments of $7.18 \pm 0.69 \mathrm{~cm}, 7.06 \pm 0.646 \mathrm{~cm}$ and $6.84 \pm 0.70 \mathrm{~cm}$ respectively. According to [8] the AMF genera Gigaspora and Scutellospora produce only arbuscules with extensive intraradical and extraradical hyphal networks whereas Glomus, Entrophospora, Acaulospora, and Sclerocystis in addition, also produce vesicles.Arbuscules are usually shortlived and begin to collapse after a few days while vesicles are storage structures and can remain in roots for months or even years [4]. 


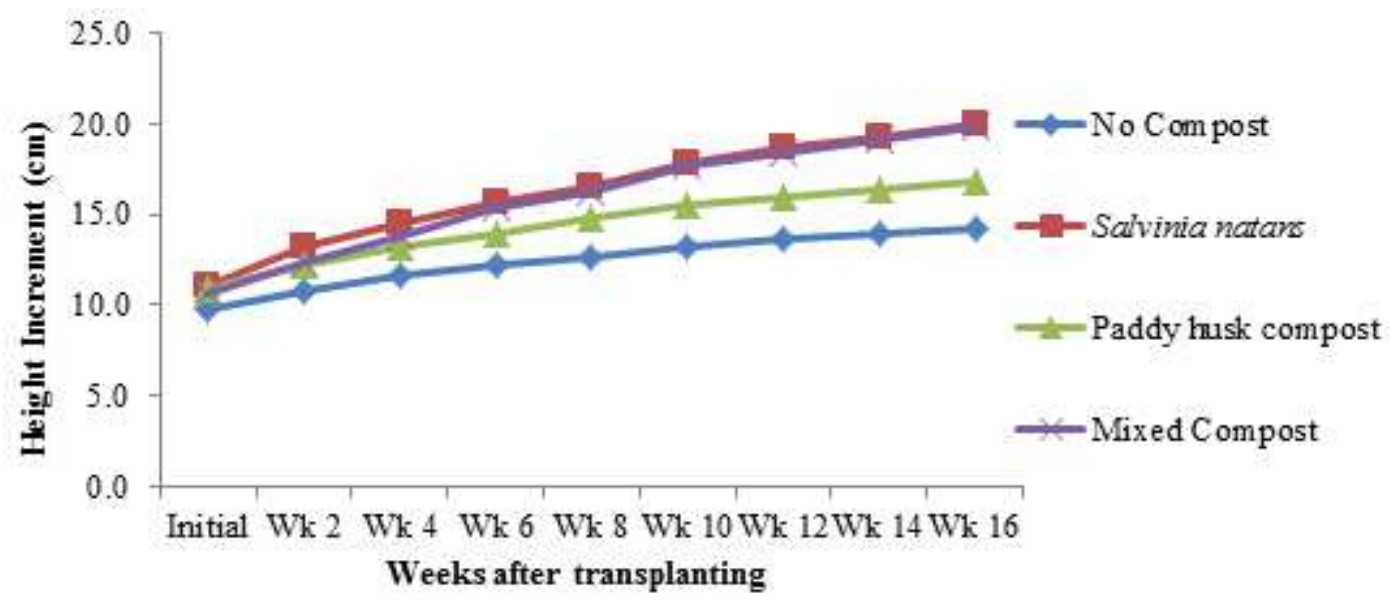

Figure 2. Effect of compost treatment on height increment (cm).

\subsection{Diameter Increment}

Increase in plant diameter or girth has often been considered as a secondary growth. However, with the addition of organic materials this process can be hastened. Analysis of Variance (ANOVA) tested at $\alpha \leq 5 \%$ showed a significant effect $(\mathrm{P} \leq 0.000)$ of compost on the mean plant diameter increment with steady increment for the study period. There was no significant effect $(\mathrm{P}=0.148 ; 0.188)$ of mycorrhizae treatment as well as the interaction between both factors on diameter increment (Table 3). In terms of diameter increment, compost from $S$. natans recorded the highest mean increment of $3.61 \pm 0.238 \mathrm{~mm}$ although there was no significant difference between the means of $S$. natans (C1) and mixture compost (C3) according to Tukey's Honest Significant Difference (HSD) method at $95.0 \%$ confidence (Table 5). There was however percentage increment of between 9 and $48 \%$ of compost treatment over the control experiment.

Although soil may vary considerably in structure and in physical, chemical and biotic properties, the rate of growth of a seedling is influenced by those properties of the soil. From the soil, the plant derives its nutrients and it is a storehouse for water and oxygen, all of which are necessary for the physiological processes associated with growth. Hence the relative abundance of these factors in a particular soil, determine the rate at which the seedling will grow [3].Plants need a number of essential elements to enable them to grow and reproduce. Plant macronutrients (primary nutrients) including Nitrogen (N), Phosphorus (P) and Potassium (K). A laboratory test of the composts used in this study had varied levels of these nutrients (Table 1) and they are needed in relatively large quantities for plants metabolic processes.

The formation of mycorrhizae induces great changes in the physiology of the roots, in the internal morphology of the plant and in the mycorrhizosphere, thus, the soil surrounding the roots [16]. The symbiotic association of AMF and plant roots has been considered to be the oldest symbiosis of plants and is suspected to ecologically be the most important symbiotic relationship between microorganisms and higher plants [24]. The fungi of vesicular-arbuscular mycorrhizae colonize considerable portions of the root system and in spite of the carbon drain they impose on the host plant, their presence within the root tissues can positively influence several aspects of the host plant's physiology. In the majority of cases, improved phosphate uptake is the primary cause of growth and yield enhancements in the mycorrhizal plants. Although according to this study mycorrhizae treatment did not significantly affect the diameter growth of $K$. anthoteca, Glomus Spp recorded the highest increment and this is due to the fact that mycorrhizae produced by Glomus Spp often result in simultaneous growth in 2 directions. Also, the mycorrhizal roots have different phosphate absorption kinetics and lower threshold values than non-mycorrhizal roots. The external hyphae developing around mycorrhizae explore a large volume of soil and absorb available phosphate beyond the depletion zone at the root surface. Phosphate accumulating in the external fungal hyphae is translocated to the internal mycelium by a well-developed transport system and transferred to the host tissues mainly across the intracellular arbuscules [11]. Certain specialized enzyme activities are specifically associated with this alternative pathway of phosphate nutrition in mycorrhizal plants. Improved phosphate nutrition is not always sufficient to explain the observed effects of vesicular-arbuscular mycorrhizae on the host plant's physiology [11].

Table 3. Two-way analysis of variance for diameter increment (mm)

\begin{tabular}{llllll}
\hline Source & Df & SS & MS & F & P-Value \\
\hline Mycorrhizae & 3 & 3.11 & 1.04 & $1.86^{\mathrm{ns}}$ & 0.15 \\
Compost & 3 & 17.44 & 5.81 & $10.44^{*}$ & 0.00 \\
Interaction & 9 & 7.34 & 0.82 & $1.46^{\text {ns }}$ & 0.19 \\
Error & 48 & 26.72 & 0.56 & & \\
Total & 63 & 54.61 & & & \\
\hline
\end{tabular}

* Significant at alpha $(\alpha) \leq 5 \%{ }^{\mathrm{ns}}$ not significant

According to [4], the primary aim of mycorrhizal inoculation is to increase the yield of plants grown for plantation forestry. These growth responses however, depend on the mycorrhizal dependency of the host plant species, soil properties; especially the availability of nutrients such as $\mathrm{P}$ and the capacity of the fungi to provide benefits to the host 
plant. Since there is relatively no difference between the amount of phosphorus in the soil and applied composts the effect of mycorrhizae on the diameter increment of $K$. anthoteca may not be remarkable. Although there was no significant different among the means of the mycorrhizae treatment on diameter increment of $K$. anthoteca, Glomus spp had the highest mean increment of $3.25 \pm 0.17 \mathrm{~mm}$ compared to Gigaspora spp, mixed culture and non-mycorrhizal plants recording increment of $2.65 \pm 0.12 \mathrm{~mm}$. Aside the factors mentioned above, soil temperature and moisture contents are other factor limiting the full potential of AMF [4]. The study site is quite critical with some extreme environmental conditions such as high temperatures leading to low soil moisture due to high evaporation rates even after watering. According to [20] of all the factors controlling seedling growth, water is the most critical. Water is the vehicle for all physiological and biochemical processes through which life is maintained. In the plant, opposing effect of transpiration and water absorption controls water. Whenever transpiration is greater than absorption, the plant becomes dehydrated. A decrease in hydration of protoplasm of cells in the meristematic tissues usually results in cessation or checking of cell division or cell enlargement or both. There is considerable variation between and within species of fungi in their response to those factors. The capacity of fungi to produce soil hyphae is thought to be a major determinant of mycorrhizae fungus benefits to their host and would result from inherent properties of the fungi and interactions with soil conditions [5].

\subsection{Leaf Count}

Unlike animals, plants only have 3 organs namely; the roots, the stems and the leaves with the stems and leaves together forming the shoot of the plant. Leaves differ from stems in that, they do not have an apical meristem, thus, leaves are determinate (limited in their growth), while stems are indeterminate (theoretically capable of growing forever). In this study, analysis of variance of compost application showed a significance effect (Table 4). The same was observed for both height and diameter increments with significant differences among the various compost types
(Tukey HSD, $\mathrm{p}<0.05$ ). The growth of plants depends on the availability of nutrients from the soil. Prolonged uptake of nutrients by either growing plants or excavation of the land for any purposes depletes soil of vital nutrients, adversely affecting the growth of plants [25]. In this study, plant biomass (leaf count) was substantially increased when green waste compost ( $S$. natans) was used as the organic matter component instead of paddy husk. It has been shown previously that increasing the organic fraction of a substrate increases plant growth [19]. Compost application in the research showed a significant increment in the number of leaves (Fig. 3). However, compost prepared from green waste such as $S$. natans was significantly different from the other compost (Table 5).

Table 4. Two-way analysis of variance for leaf increment

\begin{tabular}{llllll}
\hline Source & Df & SS & MS & F & P-Value \\
\hline Mycorrhiza & 3 & 19.81 & 6.60 & $2.60^{\text {ns }}$ & 0.06 \\
Compost & 3 & 135.06 & 45.02 & $17.71^{*}$ & 0.00 \\
Interaction & 9 & 13.06 & 1.45 & $0.57^{\text {ns }}$ & 0.81 \\
Error & 48 & 122.00 & 2.54 & & \\
Total & 63 & 289.94 & & & \\
\hline
\end{tabular}

* Significant at alpha $(\alpha) \leq 5 \%{ }^{\mathrm{ns}}$ Not significant

As indicated in other plant parameters earlier, mycorrhizae effect in this study did not significantly affect the growth of $K$. anthoteca on the field. In recent times, there have been a number of cases which indicate that AM colonization does not result in any increases in growth or in total plant $\mathrm{P}$, and sometimes the AM plants are smaller than the non mycorrhizal controls $[15,28]$. There is therefore a continuum of responses from strongly positive to negative, indicating considerable 'functional diversity' in AM symbioses [14]. The AM-responsiveness in terms of plant growth is determined by properties of the plant genome such as development of extensive root systems and long root-hairs that enhance $\mathrm{P}$ uptake by the plant when it is nonmycorrhizal, the AM fungal genome, thus, inherent extensiveness of external hyphae and other features and plant-fungus genomic interactions [28, 29].

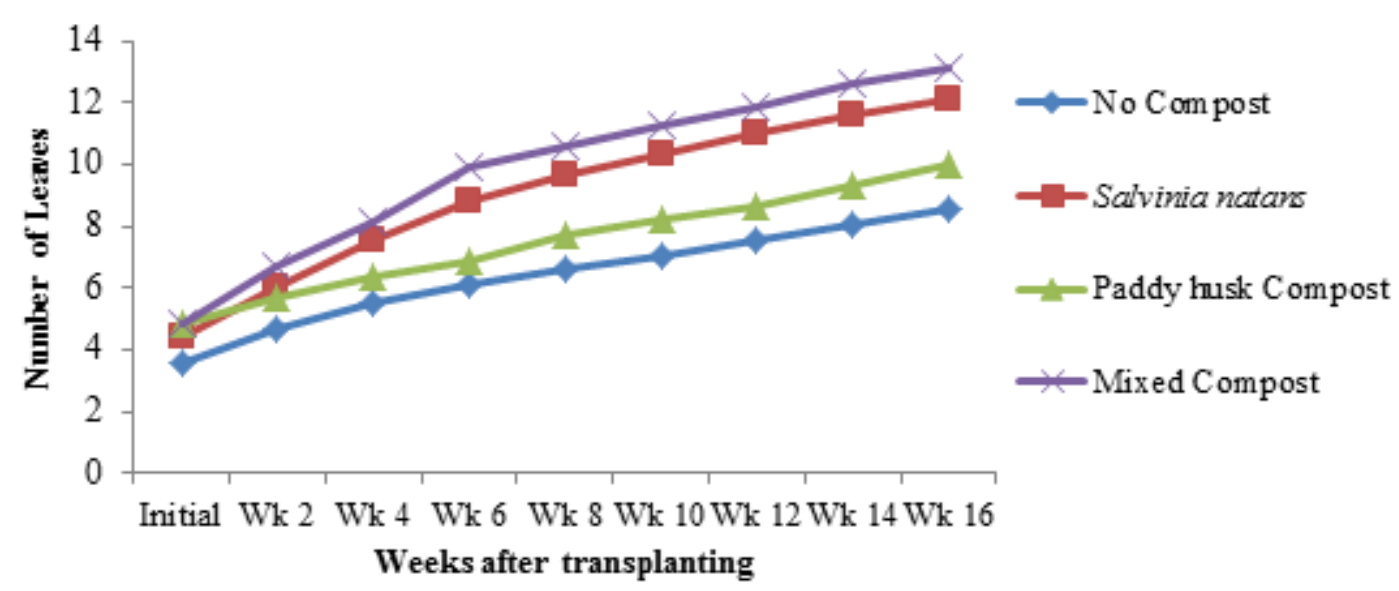

Figure 3. Effect of compost treatment on leaf counts 
Table 5. Grouping information for compost treatment means for measured plant parameters using Tukey's HSD method at 95\% confidence.

\begin{tabular}{lllll}
\hline \multirow{2}{*}{$\begin{array}{l}\text { Compost } \\
\text { Treatments }\end{array}$} & N & \multicolumn{3}{c}{ Mean \pm SE Mean } \\
\cline { 3 - 5 } & & Height $(\mathbf{c m})$ & Diameter $(\mathbf{m m})$ & Leaf Count \\
\hline $\mathrm{C} 0$ & 16 & $4.47 \pm 0.22^{\mathrm{b}}$ & $2.44 \pm 0.15^{\mathrm{b}}$ & $5.00 \pm 0.29^{\mathrm{b}}$ \\
$\mathrm{C} 1$ & 16 & $9.00 \pm 0.45^{\mathrm{a}}$ & $3.61 \pm 0.24^{\mathrm{a}}$ & $7.69 \pm 0.45^{\mathrm{a}}$ \\
$\mathrm{C} 2$ & 16 & $5.78 \pm 0.42^{\mathrm{b}}$ & $2.53 \pm 0.19^{\mathrm{b}}$ & $5.19 \pm 0.32^{\mathrm{b}}$ \\
$\mathrm{C} 3$ & 16 & $9.31 \pm 0.47^{\mathrm{a}}$ & $3.42 \pm 0.20^{\mathrm{a}}$ & $8.25 \pm 0.51^{\mathrm{a}}$ \\
\hline
\end{tabular}

Means that do not share a letter in the same column are significantly different at a confident of $95 \%(\alpha \leq 5 \%)$

\subsection{Survival of Khaya anthoteca under Field Conditions}

After four months of transplanting vegetatively propagated $K$. anthoteca to the field, non-mycorrhizal (NM) treatment recorded the highest mortality of $56.25 \%$ with only $43.75 \%$ plants surviving while $K$. anthoteca propagules preinoculated with Glomus manihotis had the highest percentage survival of $81.25 \%$. There were significant differences between NM plants and AMF inoculated plants as well as between the various AM treated plants on the percentage survival of $K$. anthoteca according to a t-test analysis for independent samples. However, there were no significant differences between compost and mycorrhizal applications on the percentage survival of $K$. anthoteca $\mathrm{P}(\mathrm{T} \leq \mathrm{t}, 0.90)$ although the mean percentage survival of mycorrhizal treatment was higher $(64.06 \%)$ than the application of compost treatment $(62.5 \%)$. Association of fungi with plant roots has long been documented and they function as plants root hair and acting as an extension of the root system [18]. The beneficial effects of AM fungi result from one or several mechanisms. With mycorrhizal colonization in the roots, there is increased absorption surface area, greater soil area exposed for longevity of absorbing roots, better utilization of low-availability nutrients and better retention of soluble nutrients, thus reducing reaction with soil colloids or leaching losses $[18,26]$. The arbuscular mycorrhizae fungi increase establishment, nodulation and atmospheric nitrogen fixation capacity in [30]. Mycorrhizae influence the colonization of roots by other microorganisms, and reduce the susceptibility of roots to soil-borne pathogens such as nematodes or phyto-pathogenic fungi [26]. The study area for this research is characterized by high temperatures with low soil moistures hence propagules with AMF inoculation were more tolerant as compared to NM. According to [18] AM also modify soil-plant-water relations, thus promoting better adaptation of plants to adverse conditions, such as drought, salinity or heat stress. At elevated heavy metal concentrations in soils, mycorrhizal fungi have been shown to detoxify the environment for plant growth. Many studies have again, indicated that AM symbioses can significantly alter plant water relations, but the reported effects have not been consistent between different investigations and mechanisms are not clear. Nonetheless, an extensive review by [2] covering hundreds of studies, highlights a number of trends in AM compared to non-mycorrhizal (NM) plants growing under water restrictions in pot experiments. These studies include increased drought tolerance, greater depletion of soil water, higher stomatal conductance and transpiration, better supply of diffusion-limited nutrients in dry soil and lower drought stress (assessed as reduced concentrations of xylem abscisic acid in AM plants). Such differences suggest that AM plants are under less stress in dry conditions than NM controls [9]. Some studies have also indicated that, improved nutrition of AM compared with NM plants may be the main basis for improved drought tolerance. About $80 \%$ of the studies assessed by [2] also revealed AM plants grow better under drought stress than NM plants.

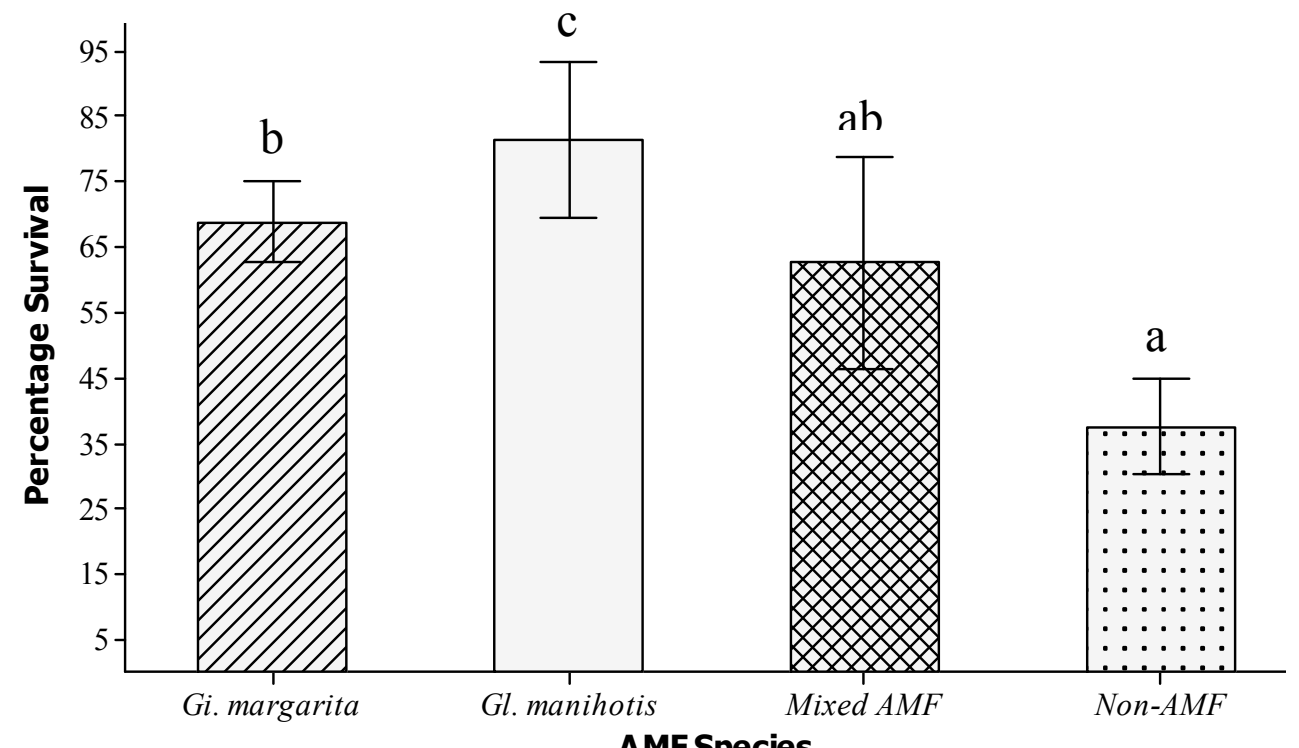

Figure 4. Effect of mycorrhizae treatment on percentage survival of Khaya anthoteca 
In this study, Glomus manihotis inoculation recorded a higher percentage survival compared to Gigaspora margarita and mixed inoculums (Glomus manihotis and Gigaspora margarita) inoculations. A study conducted by [12] on the effect of inoculation of two arbuscular mycorrhizal fungi, alone and in combination on the establishment and growth of Acacia auriculiformis in a wasteland soil, studied under nursery and field conditions showed that Acacia auriculiformis exhibited a maximal mycorrhizal dependency of $79.6 \%$ on dual inoculation. Mycorrhizal dependency differed with AM fungal isolates and age of the plant. Under field conditions, AM colonization of A. auriculiformis enhanced tree survival rates $(85 \%)$ after transplanting. Arbuscular mycorrhiza-colonized plants showed significant increase in height, biomass production and girth as compared to non-mycorrhizal plants. The study concluded that, mycorrhizal symbiosis play vital role in helping $A$. auriculiformis to establish and thrive in alkaline wasteland soils. Hence, the nursery inoculation programs with selected AM fungal species or combination of synergistically interacting species may be helpful to produce vigorous seedlings to survive under wasteland stress soil [12]. In this study however, the species used for the pre-inoculation were from two different genera, thus, Glomus and Gigaspora and a mixture of these two microorganisms therefore may therefore not be synergic and competing for the same resources under critical field conditions.

\section{Conclusions}

Mycorrhizal fungi play critical roles in nutrient cycling and terrestrial ecosystem functioning. Mycorrhizae improve plant growth through increase supply of nutrients to plant, enhance water uptake efficiency. Again, some of the benefits of inoculating with mycorrhizal fungi include; improved plant establishment rates, increased drought resistance, decreased transplant shock and improved survival. Furthermore, the addition of composted residue is an effective treatment for increasing rhizosphere aggregate stability. $K$. anthoteca is an important tropical tree species with high economic value and this study has shown that the species can be established on ex-coal mined sites. Base on the outcome of this study therefore, stem cutting of $K$. anthoteca pre-inoculated with AMF and compost applications can be established on ex-coal mined sites. Compost made from organic materials such as $S$. natans is preferable for the growth and development of the plants with application rate of $5 \mathrm{Kg} / \mathrm{plant}$ and the propagules at heights of at least $30 \mathrm{~cm}$ tall. Nonetheless, other aquatic weeds for composting and subsequent application should also be experimented. Again, the results of this study should be ascertained through the establishment of $K$. anthoteca in other mining sites to widen its application for revegetation. Finally, it must however be emphasized that, $K$. anthoteca can also be established on the field (ex-coal mined sites) without mycorrhizae inoculations. On the other hand, inoculation will help facilitate the reintroduction of these soil microorganisms into the ecosystem.

\section{Acknowledgment}

We are grateful to God for His divine protection. Special thanks to all staff of PT. Bukit Asam (Tanjung Enim, South Sumatra) especially Mr. Muhamad Bagir and Dedy Rosa for their immense assistance during the field work

\section{References}

[1] Al-Karaki GN. 2006. Nursery inoculation of tomato with arbuscular mycorrhizal fungi and subsequent performance under irrigation with saline water. Scientia Horticulture 17:109

[2] Augé RM. 2001. Water relations, drought and vesicular arbuscular mycorrhizal symbiosis. Mycorrhiza 11:3-42. doi:10.1007/s005720100097

[3] Brady NC, Weil RR. 2008. The Nature and Properties of Soils. $14^{\text {th }}$ Ed. Prentice Hall. NJ Pp 462.

[4] Brundrett M, Bougher N, Dell B, Grove T. and Malajczuk N. 1996. Working with Mycorrhizae in Forestry and Agriculture. AClAR Monograph. Pirie Printers, Canberra, Australia Pp $179-185$

[5] Brundrett MC. 1991. Mycorrhizae in natural ecosystems. In: Macfayden A, Begon M, Fitter AH (ed.), Advances in Ecological Research. Vol. 21 Academic Press, Londen, 171-313.

[6] Caravaca F, Herna'ndez T, Garci'a C, Rolda'n A. 2002. Improvement of rhizosphere aggregate stability of afforested semiarid plant species subjected to mycorrhizal inoculation and compost addition. Geoderma (Elsevier) 108 133- 144

[7] Cunha LO, Fontes MAL, Oliveira AD, Oliveira-Filho AT. 2003. Análise multivariada da vegetac, ão como ferramenta para avaliar a reabilitac, ão de dunas litorâneas mineradas em Mataraca, Paraíba, Brasil. Revista Árvore 27, 503-515.

[8] Douds DD, Millner PD. 1999. Biodiversity of arbuscular mycorrhizal fungi in agroecosystems. Agric. Ecosyst. Environ. $74,77-93$

[9] Duan XG, Neuman DS, Reiber JM et al,. 1996. Mycorrhizal influence on hydraulic and hormonal factors implicated in the control of stomatal conductance during drought. Journal of Experimental Botany 47:1541-1550. doi:10.1093/jxb/47.10.1541

[10] European Commission. 2001. Applying Compost; benefits and needs. Seminar proceedings Brussels, 22-23 November 2001. Brussels, Belgium. P 128.

[11] Gianinazzi-Pearson V, Gianinazzi S. 1983. The physiology of vesicular-arbuscular mycorrhizal roots. Plant and Soil, Springer 71: 1-3, Pp 197-209

[12] Giri B, Kapoor R, Agarwal L, Mukerji KG. 2004. Preinoculation with Arbuscular Mycorrhizae Helps Acacia auriculiformis Grow in Degraded Indian Wasteland Soil. Communications in Soil Science and Plant Analysis. Marcel Dekker, Inc. 35:1, 2 Pp. 193-204 
[13] Hawthorne, W. 1998. Khaya anthotheca. The IUCN Red List of Threatened Species. Version 2014.3. www.iucnredlist.org.Downloaded on 24 January 2015.

[14] Jakobsen I, Smith SE, Smith FA. 2002. Function and diversityof arbuscular mycorrhizae in carbon and mineral nutrition. In: van der Heijden MGA, Sanders IR (eds) Mycorrhizal ecology. Springer-Verlag, Berlin, Heidelberg, pp 75-92.

[15] Johnson NC, Graham JH, Smith FA. 1997. Functioning of mycorrhizal associations along the mutualism-parasitism continuum. New Phytologist. 135:575-586. doi:10.1046/j.1469- 8137.1997.00729.x

[16] Martin F, Perotto S, Bonfante P. 2007, Mycorrhizal fungi: A fungal community at the interface between soil and roots, pp. 201-236. In R. Pinton, Z. Varanini, and P. Nannipieri (Eds.), The rhizosphere: Biochemistry and organic substances at the soil-plant interface. Marcel Dekker, New York.

[17] Mohr H. and Schopfer P. 1995. Plant physiology, SpringerVerlag, Berlin Heidelberg, Hong Kong. Pp 294.

[18] Muchovej RM. 2004. Importance of mycorrhizae for agricultural crops. SS-AGR-170, Agronomy Department, Florida Cooperative Extension Service, Institute of Food and Agricultural Sciences, University of Florida.

[19] Nagase A, Dunnett N. 2011. The relationship between percentage of organic matter in substrate and plant growth in extensive green roofs. Landsc. Urban Plan. 103, 230-236.

[20] Nwoboshie LC. 1982. Tropical silviculture: principles and techniques. Ibadan University Press. 333pp.

[21] Ortas I. 2006. Mycorrhizae inoculated seedling production systems inorganic farming under greenhouse and field conditions. 5th International Conference on Mycorrhizae ICOM5 Mycorrhiza for Science and Society, 23-27 July, Granada, Spain.
[22] Ouédraogo EA. Mando, Zombré NP. 2001. Use of compost to improve soil properties and crop productivity under low input agricultural system in West Africa. Agriculture, Ecosystems and Environment (Elsevier) 84 259-266.

[23] Pamerindo Indonesia. 2015. A Pamerindo Indonesia Trade Event. The 17th International Mining and Minerals Recovery Exhibition and Conference, Jakarta International Expo, Kemayoran Jakarta-Indonesia. 9-12 September, 2015.

[24] Paszkowski U. 2006. A journey through signaling in arbuscular mycorrhizal symbioses. New Phytol. 172, 35-46.

[25] Russell EW 1998. Soil condition and plant growth. $11^{\text {th }}$ edition, Longman Publication, UK. Pp 34.

[26] Selvaraj T, Chelleppan P. 2006. Arbuscular mycorrhizae: a diverse personality, Central Eur. J. Agr. 7, 349-358.

[27] Singh V, Singh TN. 2004. Environmental impact due to surface mining in India. Minetech, 25, 3-7

[28] Smith FA, Grace EJ, Smith SE. 2009. More than a carbon economy: nutrient trade and ecological sustainability in facultative arbuscular mycorrhizal symbioses. New Phytol.doi:10.1111/j.1469 8137.2008.02753.x

[29] Smith SE, Read DJ. 2008. Mycorrhizal Symbiosis, 3rd ed. Elsevier and Academic, New York, London, Burlington, San Diego.

[30] The United States Composting Council. 2008. USCC Factsheet: Compost and Its Benefits. Ronkonkoma, NY. Pp 12

[31] Turk MA, Assaf TA, Hammed KM, Al-Tawaha AM. 2008. Significance of mycorrhizae, World J. Agric. Sci. 2, 16-20. 